\title{
Research on Digital Music Composition Technology
}

\author{
Sen Yang \\ Aba Normal University, Aba Prefecture, Sichuan, 623002
}

Keywords: digital music; composition technology; music development

\begin{abstract}
Digital music, commonly known as computer music, refers to music created and produced with computer. The combination of computer and music can be traced back to the formulation of the first set of standards. In this year's development of digital music, many new standards, more and more advanced, and the more and more widespread scope of applications have been produced, from the earliest single MIDI synthesis, to digital audio, to soft audio sources, and then to music recording mixing by many channels, and it can be said that the computer can simulate any sound in nature, but also create a sound that nature does not have, greatly enriching the music material. It cannot be seen that in this development process, the impact of digital music on music creators is also enormous. Music creators can quickly record the next flash of inspiration, and can also use computers to debug various interesting sounds and enrich their works. At present, digital music has become an increasingly important method in the creation and production of music, and has even become an indispensable creative method for composers.
\end{abstract}

\section{Introduction}

In the nearly 30 years since 1980, there has been a major revolution in the field of science and technology that is changing the way people live. This is the Digital Revolution. The sign of the digital revolution is the transformation from computer simulators and electronic technologies to digital technologies. It also includes large-scale technological changes brought about by digital computing technology and digital communication technology since the second half of the 20th century. Just as the agricultural revolution and the industrial revolution each created a new era of human social development, the digital revolution marks the beginning of the Information Age. 1 The core content of this technological revolution is the invention and breakthrough development of "digital logic circuits" and "microprocessors". Relying on these two basic technologies, digital electronic computers and personal computers are widely used as socialized products, and digitized portable telephones, digital cameras, fax machines, electronic keyboards, etc. are promoted by digital computer technology. Mass production and wide application of information and entertainment products. Equally important is the development of a series of transmission technologies including computer networks, the Internet and digital broadcasting, and 3G telephony. The transformation and development of these science and technology and the social popularization of their corresponding products have not only changed the structure of industrial production in the past, but also changed the way of information exchange in society, and, to a great extent, has also changed people's way of life.

\section{Digitalization of Music Production}

Music is the art of sound. The sound of music is the music itself. Therefore, the complete product of music production should be a musical work presented in sound form. That being the case, the music production we are talking about here includes not only composing (composition creation) but also singing or playing activities that can make music sounds appear. It should also include the use of digital technology (mainly relying on computers) to produce directly. Music sound production of various types of music creation and production methods. Due to the influence of western writing (music) music creation methods and ideas, our composers have had to "create" music (design and write notes) on the music sheets for a long time, and then send them to the band or performer to 
perform the musical notation " "Decode" ("spectrum") and "restore" (visit, see) the music sound. In fact, except that a large number of traditional music does not require such a creative pattern, modern music has been developed from music scores and has been used to create musical sounds directly from computers and electronic musical instruments for over half a century. However, in the early stages of the experiment, people mainly used analog recording and electronic means to create music. Although in the mid-1960s the electronic music revolutionized the invention of a voltage-controlled synthesizer7, the production of music was still relatively low, as the computer did not play a leading role in music production at that time. Low technical level. Until the 1990s, with the development and popularization of digital computers, computers have gradually become the core equipment for electronic music creation and production, making music creation and production into a convenient, high-quality digital era. Since 2000, due to the continuous improvement of computer digital computing speed and the continuous upgrading of multimedia functions and storage hardware, especially the development of professional audio interfaces (audio cards, computer digital audio processing hardware), composers can not only be more convenient on computers. Processing MIDI data and processing large-capacity digital audio data at the same time makes it possible to "produce" high-quality music products even with a personal computer (microcomputer) and peripheral music equipment [1]. At the same time, a large number of high-performance digital music software for computers (including music workstation program software, recording/mixing software, software audio sources, and software effects, etc.) has emerged, and it is completely possible to independently use such music software on computers. Instrumental music, audio recording, texture editing, audio modulation, and all procedures for disc burning. At this point, once the composer had a high-profile personal computer and digital music software loaded into it, it meant that he had a "factory" that produced musical works. Social production of music in the past, such as written by a composer first, then performed by a large band, choir or solo, solo singer in a concert hall and other occasions, or by recording live music through a large recording studio , Then the record factory produces the pressure plate for the recording master tape, etc. It can be turned into an individual production method by this simple digital machine (personal computer). It can be seen that the application of digital technology in the production of music products has not only changed the technical means of music creation in the past, but also changed the way of music creation due to the improvement of technical means, and thus changed the creative concept and performance of music that is different from traditional composition. Technique. With regard to the current practice of using computers for music creation (production), the types of music created include commercial pop music, film and television music, and various practical music (such as advertising scores, video game music, etc.), as well as pure music fields. Experimental electronic music, serious music. No matter what genre or use of music is created, they are the result of digital technology and all have the characteristics of digital music creation and production. As Liu Yuquan summarized the features of current computer music creation in the "Composer of the Third Kind" 8 , it mainly manifests itself in several aspects: (1) the integration of composition, performance, and production; (2) the visual experience of auditory art (3) Mosaic combination of music graphics; (4) three-dimensional arrangement of linear thinking; (5) unlimited possibilities of audio material. 9 In addition, we say that music production also includes music performance activities. In fact, in the digital era, many real live music performances in the past can also be presented digitally. For example, pure-voice recording playback and video/audio-video playback are all based on digital technology, and the virtuality (acoustic-optical effect through electrical appliances) is digitalized. Of course, the digital presentation of the final product of this music performance is based on the premise of the previous real (live performance) recordings, but the recording process still cannot avoid the digitization process [2]. In the process of music creation and production, live performances are required when real human voices and real musical instruments are required for recording. However, when such performances are recorded on a machine, they are digitally processed through a "modular $\rightarrow$ digital" type to become digital audio signals. When music production and production do not require "real sound" (human voice and acoustic instrument sound) recording, songwriters can "synthesize" directly through digital audio technology to complete the 
final production (production).

\section{The Digital Way of Music Transmission}

As early as analog recording technology and radio technology were invented, music sounds can be transmitted independently from live live performances and rely on media (records, tapes, radio, television, movies, etc.) to spread independently. The influence of the digital revolution on the propagation of this medium is mainly reflected in the optimization of the quality of the media and the music it carries through digital technology. For example, digital compact discs are optimized for old-fashioned "gramophone records"; radio digital broadcasting is an optimization of previous "analog broadcasting"; digital television is for analog images and audio. Signal optimization and so on. In addition to this, the spread of online music that accompanies the digital era relies heavily on mp3 music files in the digital audio compression format, which is the dissemination of purely digital music information. The more widespread channels of communication are also dependent on the download transmission of digital audio music works by "cell phones" (network digital audio signal transmission based on wireless network systems) [3].

As mentioned earlier, the digitization of music is not only an "operational" method used in the production of musical products, it also has a more important influence on the "storage" and "transmission" of musical sounds. In the process of rendering digital music works, although physical materials (such as computers, headphones, speakers, disks, etc.) are also required to "trigger", it is not parasitic in these material materials, but merely "stored" with intangible digital information. Storage media. It can freely transfer storage media, and it can also copy backups. More importantly, it is able to carry out convenient network transmission in the form of "send", and after a piece of music is "sent", the work itself still exists in its place-this is totally different from the record in the form of matter. The transmission. Propagation is not limited by time, space, and capacity, and it spreads online in a timely, timely, high-fidelity, high-capacity, and time-space-constrained manner. This is where intangible digital music products differ from tangible physical media music products. Transmission characteristics. It is precisely because digital music products can be copied and stored in an unlimited amount and easily spread, thus affecting the unprecedented maximum consumption of social music [4].

From the perspective of sociology of music, music consumption includes people's appreciation of music products (works), the use of music by social groups (such as for celebrations, ceremonies, setting off atmosphere, setting off the environment), and so on. In addition to the traditional live performances of concert halls and theaters, the most popular or popular methods are: listening to music and playing on computers; watching MV videos, watching television, and movies Music) etc. From the perspective of economics, music products have the attributes of commodities when they are paid for as consumer goods. In other words, because the musical work (sound finished product) has a use value, it requires the user to pay for it. However, music works as a special product. People use it or consume it in a special way. Therefore, they can often be obtained free of charge, such as listening to music played on the radio, watching music played on the TV, and so on. This tradition of gratuitous consumer music products has been further strengthened in the digital era, and it is the convenient spread of digital music products and the easy accessibility of digital audio information to promote this phenomenon [5]. Among them, "facilitating the dissemination" benefits from the convenient dissemination of digital information in the mass media, and "easy access" is related to the storage of digital music information and the popularization of digital devices (mainly personal computers).

\section{Conclusion}

In the era of industrialization, as in the production of atomic products, the products produced in a bit-mode in the digital era must also comply with the principle of standardization in order to achieve unity of mass production and consistency of wide application. In contrast to the era of industrialization, products produced in a bit-type manner do not require large-scale production tools 
such as large factories, and bit-production is more miniaturized and personalized. However, the scope of application of products is far superior to that of atomic substances in the industrialized era. product. The modern music industry (recording industry) has a basic principle of commercial operation, that is, "to sell as many commodities as possible to as many consumers as possible." In the industrial era, the distribution of analog recordings complied with this commercial principle, while the digital recording products in the information age were gradually broken down due to the individuation of music production and the convenience of online communication. Music production and music consumption were gradually broken down. The diversity and personalization are rapidly replacing the scale and unity of the industrial age. The social existence of music and people's understanding of music products are changing. Digital music products will be more dependent on intangible "bit" numbers, will gradually get rid of the "atomic" material binding on it, will not be tangible "products" and intangible "information" as the identity of this information age.

\section{References}

[1] Yang Jiameng, Cai Zhijian. Analysis of the development of digital music industry in China [J]. Contemporary Economy. 2008 (01)

[2] Song Yu. Application of Music Software in Digital Music Education and Cross-discipline [J]. Art Education. 2009 (02)

[3] Jin Wen. On the development of China's digital music industry [J]. Journal of Jiangxi Finance and Staff University. 2010 (01)

[4] Zhang Hailian. Analysis of the Status Quo and Development of Digital Music Industry in China [J]. Journal of Huaihai Institute of Technology (Social Sciences Edition). 2010 (03)

[5] Yuan Xuefeng. Piracy: The biggest obstacle to the development of the digital music industry [J]. Audio-visual industry. 2011 (06) 